\title{
Analysis of disaster resilience of urban planning facilities on urban flooding vulnerability
}

\author{
Kiyong Park ${ }^{1}$, Hoo $\mathrm{Oh}^{1}$, Jeong-hun Won ${ }^{+}$ \\ ${ }^{1}$ Department of Disaster Prevention, Chungbuk National University, Chungdae-ro 1, Seowon-gu, Cheongju, Chungbuk, 28644, Republic of Korea \\ ${ }^{2}$ Department of Safety Engineering, Chungbuk National University, Chungdae-ro 1, Seowon-gu, Cheongju, Chungbuk, 28644, Republic of Korea
}

\begin{abstract}
Rainfall continues to increase due to the influence of global warming and is resulting in an increase in flood damage. The purpose of this study is to propose an approach for reducing urban flood damage and improving urban resilience. Urban flooding vulnerability analysis used land use and building characteristics as evaluation indicators. Disaster resilience analysis of urban planning facilities focused on urban and spatial aspects. The results of these analyses were overlapped to analyze whether urban planning facilities were properly located in areas vulnerable to urban flooding. The result of mapping the two results showed that there are some urban planning facilities with low resilience in the Red Zone, the central commercial area of Changwon, which has the highest vulnerability. This zone should have the appropriate placement of high-resilience facilities, such as disaster prevention facilities and space facilities. This study proposes a method to minimize flood damage in urban space. This system can cope with and systematically manage flood damage by increasing disaster resilience through appropriate land use planning and site selection for urban planning facilities.
\end{abstract}

Keywords: Climate change, Resilience, Urban flood, Urban planning facilities, Vulnerability

\section{Introduction}

Global warming is believed to be one of the main reasons for the increase in frequency and magnitude of extreme rainfall events (therefore floods), since a warmer atmosphere with enhanced humidity leads to a more active hydrological cycle [1]. Katz and Brown [2] stated that even a small change in the mean rainfall due to global warming can cause significant changes, resulting in extreme rainfall events. Additionally, urbanization is another factor that increases intensity and frequency of floods. The effects of urbanization and global warming on floods will increase in the future, due to an expansion of urbanization to accommodate increased population and to increases in greenhouse gas emissions [3]. Cities are complex and interdependent systems, extremely vulnerable to threats from natural hazards. The very features that make cities feasible and desirable - their architectural structures, population concentrations, places of assembly, and interconnected infrastructure systems - also put them at high risk to damage from floods [4].

Land use law (Derecho urbanístico, in Spanish, or Droit de l'urbanisme, in French) is the regulation of the use and development of public and private real estate. There is a clear relationship between the way that land is used and its vulnerability to disasters. On one hand, the regulation of land can promote urban expansion by means of several instruments, such as planning and zoning. Urban expansion can bring more intensive use of land, industrial development, and construction of infrastructure that can be a factor in future disasters. A good example of this is urban pressure on rivers and flood risks. On the other hand, the proper regulation of land can be a tool for the prevention of disasters and can minimize their impacts when disasters are unavoidable. Traditionally, that point of view has not been explored in depth by European jurisprudence [5].

The key issue that is addressed in this study is the development of damage-reducing measures through urban planning. To this end, a vulnerability analysis was conducted first, considering land use and building characteristics. The analysis can be used to build a plan for damage reduction through urban planning, prioritizing the types of land use based on their vulnerability. A second analysis was then performed, using the types of infrastructure (i.e., urban planning facilities) that are used in the National Land Planning

Received December 29, 2019 Accepted January 13, 2020

${ }^{\dagger}$ Corresponding author

Email: jhwon@chungbuk.ac.kr

Tel: +82-43-261-2459 Fax: +82-43-263-2409 mits unrestricted non-commercial use, distribution, and
medium, provided the original work is properly cited.

Copyright (C) 2021 Korean Society of Environmental Engineers 
and Utilization Act. Urban planning facilities are necessary for the support and well-being of urban residents and can be divided into facilities that are directly damaged by natural disasters, secondary damage facilities, and facilities that provide disaster prevention functions. This study analyzed the disaster resilience of urban planning facilities, which is an important factor for urban planning, and ranked the facilities, based on their relative resilience. The study concludes that advanced plans and measures to minimize urban flooding risks through resilient urban development and land use planning can minimize the damage caused by increased flooding in urban areas.

\section{Methods}

\subsection{Vulnerability to Urban Flooding}

The risk of disaster is discontinuous and local. The only way to reduce risk is to reduce the vulnerability within a system. The risk of flooding places stress on the urban system, but is purely natural and is caused by variations outside of the system. There is nothing that people can do to reduce the risk itself. Human beings can only reduce the vulnerability to natural disasters by changing social systems or social infrastructure [6].

In general, the concept of vulnerability, as defined by the Intergovernmental Panel on Climate Change (IPCC) and the United Nations Development Program (UNDP), is used broadly for this study. The IPCC defines it as the "the degree to which a system is susceptible to, or unable to cope with, adverse effects of climate change, including climate variability and extremes." UNDP defines it as the sensitivity to the risk of exposure and the lack of ability to cope, recover and adapt to climate change and stress.

The ultimate goal of a vulnerability assessment is to identify vulnerable areas through relative comparisons between regions or sectors, and to build basic data for establishing adaptation policies. The specific goals of the assessment vary depending on the facts sought from the vulnerability assessment [7].

The purpose of a vulnerability assessment related to flooding includes the identification of vulnerable sectors and regions to assess climate impact and prioritize adaptation policies, and to develop alternatives for adaptation policies.

The recent trend of urban planning is to target the entire city, but an emerging trend places importance on urban planning that reflects regional characteristics. If precautions can be taken during the establishment of land use planning, which is an urban planning phase, it might be possible to prevent urban disasters beforehand. This study proposes a method for deriving the proper location of urban planning facilities, by evaluating urban disaster resilience, using use area in urban area as the spatial unit.

The basic method proposed by this study is to utilize regional characteristics to inform the placement of resilient urban planning facilities in areas with high susceptibility to damage and to recommend placement of urban planning facilities with lower resilience in safe areas with relatively low disaster vulnerability. The principle of this concept is shown in Fig. S1.

\subsection{Concept of Resilience}

Resilience is used in a variety of concepts for research in various fields from environment and climate change, to science, engineering, psychology, sociology, and economics. Resilience is generally defined in terms of its ability to quickly recover from shock, change or stress [8], and its meaning is mixed with marginality, sensitivity, adaptability, fragility, and risk [9]. This study examined the concept of resilience further, as it aims to find out about the resilience, i.e., the ability to overcome natural disasters such as climate change that the world faces now.

The measurement of resilience, the force that restores a part of a system or the entire system to a normal state, from economically and socially negative consequences such as damage, failure potential, loss, or damage from a disaster or shock, is generally described in Fig. 1. It is based on the concept that a measure Q ( $t$ ) that changes over time is defined for the quality of the infrastructure. In particular, performance can range from $0-100 \%$, where $100 \%$ means no degradation of infrastructure (best condition), and $0 \%$ means no usable infrastructure is available. The infrastructure will be shocked and damaged when a disaster occurs at time to, resulting in an immediate drop in quality (e.g. a vertical drop from $100 \%$ to $50 \%$ ). Restoration of the infrastructure appears to occur over time until time $\mathrm{t} 1(100 \%$ recovery), when it is completely recovered.

In other words, resilience due to disasters (R) can be measured based on the scale of infrastructure quality degradation (possibility of damage) and recovery time against the passage of time. This is expressed as Eq. (1) [9].

$$
R=\int_{t o}^{1}[100-Q(t)] d t
$$

Researchers note that resilience requires a combination of substitution, efficiency, diversity, interdependence, and flexibility through the many characteristics found in the interactive systems of the environment and society $[4,10]$. Based on these principles, Bruneau et al. [8] and Tierney and Bruneau [11] proposed the $4 \mathrm{R}$ framework of resilience, which represents the four functional goals of a resilient infrastructure (Robustness, Redundancy, Rapidity, and Resourcefulness) [4, 11].

This is in the same context as conceptualizing resilience as the ability to respond to the risk of a disaster through an effective recovery strategy, such as assessing and promptly responding to shock and damage situations due to the characteristics of the physical and social systems, and it seems to be composed of properties that can encompass physical and social systems as a whole. The functional goals and factors of resilience are described in detail in Table S1.

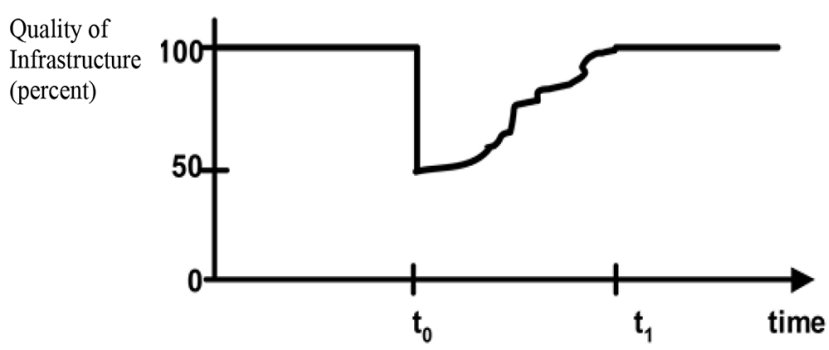

Fig. 1. Concept of resilience [9]. 
McDaniels et al. [12] suggested a conceptual framework for understanding the factors that affect infrastructure's disaster prevention features, both in terms of durability (the extent to which system functions are maintained) and rapidity (the time required to recover both system operation and productivity) [12]. However, redundancy and resourcefulness could also affect the resilience of infrastructure. This means that the robustness, redundancy, rapidity, and resourcefulness that constitute resilience according to the responsiveness after a disaster, can be intensified by pre-disaster risk reduction activities and post-disaster response activities.

Based on the meaning and characteristics of resilience that were examined so far, resilience can be defined as the ability to reduce the impact, damage, or stress inflicted on a system or a city and the ability to recover the system or the city to its previous or better state.

\subsection{Relationship Between Land Use and Resilience}

Urbanization and climate change directly and indirectly impact or cause disasters within urban spaces. Urbanization and climate change, which have relevance to all areas of urban space, are important paradigms related with natural disasters. If urbanization was the global phenomenon that drew the attention of the whole world in the 1900's, the international issue of the 2000's is climate change. The most common opinion among experts is that the influence of climate change will appear more prominently in society, along with the acceleration of urbanization [13].

Vulnerability and resilience, which are the characteristics of land use, are conceptually related in many academic areas and share commonality in many aspects. The concept of social vulnerability was suggested by O'Keefe et al. (1976), who argued that disaster damage occurs more because of socio-economic vulnerability than natural factors. He then focused on disaster damage caused by physical shocks, emphasizing that people's behavior increases vulnerability. This shift in ideas relates resilience with vulnerability and has had a significant impact on how to prevent disasters caused by physical factors. For example, the efforts to control natural environmental elements that may potentially cause disasters, such as constructing embankments on the floodplain, are being replaced by the ones that emphasize the ways to deal with unexpected disasters through the ability to adapt and overcome disaster impacts [14]. Various literature indicates that the relationship between vulnerability and resilience is either that they are directly opposite or that they are close to each other, making it difficult to establish a clear relationship. Manyena believes that whether vulnerability and resilience are positive or negative depends on the definition of terms [15]. For example, if we look at the definition of vulnerability as the ability to overcome or recover from a disaster, we see vulnerability as something very closely related to resilience. On the other hand, the Resilience Alliance, one of the main research institutions, that proposes policies for sustainable development, has defined vulnerability as something perpetuated by reduced resilience [16]. In other words, it indicates that a very vulnerable area or group has low resilience and, vice versa, indicating that resilience is a component of vulnerability and vulnerability is also a component of resilience. On the other hand, if vulnerability is regarded as exposure, threat, and potential

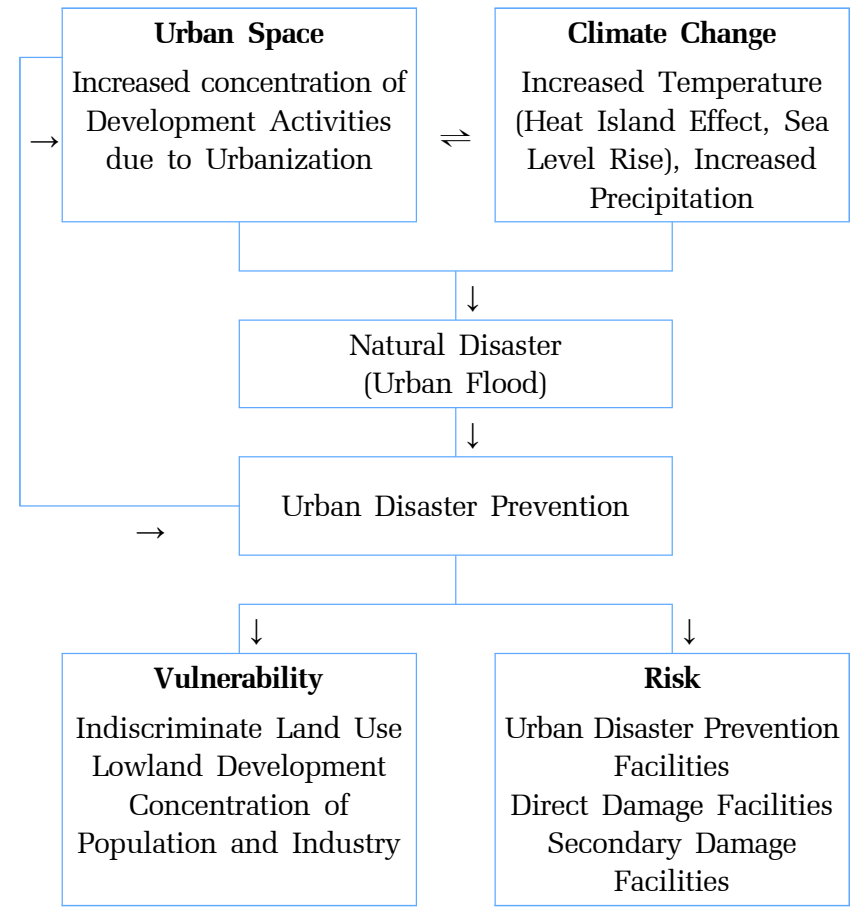

Fig. 2. Relationship between urban space and urban disaster prevention.

loss from disaster, the concepts of vulnerability and resilience are not related at all. Manyena [15] argued that the two concepts are independent of each other. Some scholars argue that they are independent of each other but have some relevance [17].

Taken together, the relationship between vulnerability and resilience is viewed from two perspectives. First, it is to see vulnerability and resilience as elements of each other, and second, it is to see them as being independent, but often connected to each other. Both the former and the latter have strong implications when studying vulnerability and resilience.

Fig. 2 shows the relationship between urban space and urban disaster prevention. Artificial factors such as population, industry, and facilities are concentrated in limited urban spaces due to urbanization, and as urbanization proceeds, urban spaces vulnerable to natural disasters increase, due to indiscriminate land use. If unexpected natural disasters occur due to climate change, urban spaces with high vulnerability and urban spaces with low resilience not only increase the risks but also form a cyclical relationship in which damage due to natural disasters recur.

\subsection{Evaluation Indicators of Resilience}

Urban planning facilities are the facilities determined by the urban management plan, from the infrastructures specified by the National Land Planning and Utilization Act, which are necessary for the lives of urban residents and the maintenance of urban functions, such as roads, parks, markets, railways, and so forth. They are classified in Table S2.

Resilience is a recovery effort made in a manner that mitigates social disruption and social risks and reduces the impact of disasters. The aim of improving resilience is to minimize damage to the quality of life and minimize injury and economic loss. Resilience 


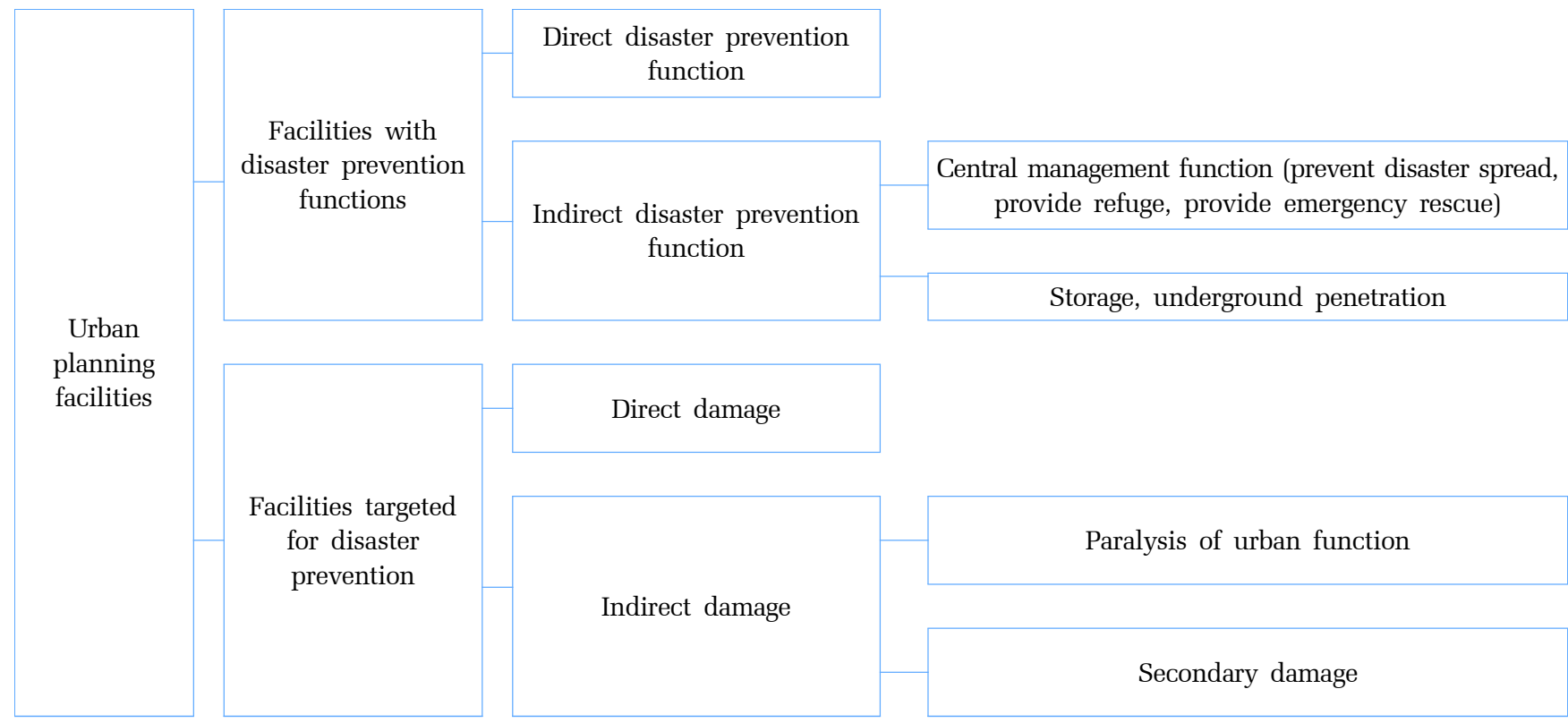

Fig. 3. Types of urban disaster prevention on the characteristics of urban planning facilities.

can be enhanced with strategies to strengthen the infrastructure functions of communities following a disaster and to effectively cope with and recover from emergency situations and local losses [9]. Based on the concept of resilience and the literature review of previous studies, the reasons that urban planning facilities are selected as an indicator of disaster resilience are as follows:

First, numerous institutions, organizations and factors contribute to the resilience of facilities. These facilities - those that ensure that there are no problems in the functional areas of the city and those that have important functions such as emergency response management - play an important role in improving resilience as a whole [9]. Second, considering damage inflicted on facilities by natural disasters during the past 10 years, from 2008 to 2017, damage to public facilities including road and infrastructure (direct damage) accounted for the largest part (69.37\%), as shown in Table S3.

Third, resilience, in terms of the technical dimension, represents the performance of a physical system in the event of a disaster [12], the physical influences (including components, interactions, and the entire system) that can affect whether a system can perform as it did originally, and the capability to manage important facilities and perform disaster-related functions [9]. Fourth, most urban planning facilities are in cities, and assets of considerable economic scale are needed to measure the resilience of urban disaster prevention. The public sector needs to invest first to prove its effectiveness.

In principle, all spaces, buildings, and facilities in the city need disaster prevention. Flood damage does not end with the direct damage to the city's spaces or facilities, but rather causes the paralysis of urban functions and secondary damage. However, there is a difference in the level of disaster prevention needed, depending on the classification of facilities as those with disaster prevention functions and those that need protection against disaster, as shown in Fig. 3.

By all accounts, urban planning facilities are the facilities derived from by the National Land Planning and Utilization Act, which are necessary for the maintenance of the lives of urban residents and for urban functions. They can be divided into facilities directly damaged by disaster and facilities that have disaster-prevention functions. The impacts on the resilience of these facilities are determined differently. This study analyzes the relationship between urban planning facilities and resilience.

\subsection{Fuzzy Classification and Analytic Network Process}

Fuzzy set theory has been developed and extensively applied since 1965 [19]. It was designed to supplement the interpretation of linguistic or measured uncertainties for real-world random phenomena. These uncertainties might originate from non-statistical characteristics in nature, with the absence of sharp boundaries on information. The main sources of uncertainties in a large-scale complex decision-making process may be properly described via fuzzy membership functions [20]. In this study, it is very difficult to express numerically which facilities are more subject to flood damage, when a flood impacts both commercial and residential areas. Using fuzzy reasoning methodology, the relationship and influence between indicators can be identified, and comprehensive land use vulnerability of urban spaces can be identified through objective, quantitative indicators.

In addition to measuring physical values for things or phenomena, this relative valuation can be useful for decision-making among alternatives. When there are several criteria and alternatives involved in making a decision, if there is a correlation between them, the Analytic Network Process (ANP) method is a very effective tool [21]. In this study, disaster recovery resilience was analyzed by applying ANP, which can reflect the objectives and criteria, alternative dependencies, and feedback for the alternatives.

\subsection{Analysis Area}

The distribution of flood damage in Korea in 2008 was analyzed 
by the Korea Ministry of Land, Infrastructure, and Transport, and is illustrated in Fig. S2 [22]. Changwon City was selected as the study area, because it includes areas with both high and low flood damage.

\section{Results and Discussion}

\subsection{Urban Flood Vulnerability Analysis}

The vulnerability analysis was based on land-use planning, and building-to-land ratios. Using fuzzy approaches, the tests focus on risks. A use area was selected for the study, in order to assess the flooding risk related to the use area - the institutional basis of land use - to analyze the degree of damage to the flooded area from the urban planning point of view and to develop a plan to minimize or reduce the damage.

As a result of the vulnerability analysis, the order of flood damage by use district was determined, as shown in Table 1 . The higher the fuzzy score, the higher the flood risk level, indicating that flood damage was greater, while the lower the fuzzy score, the

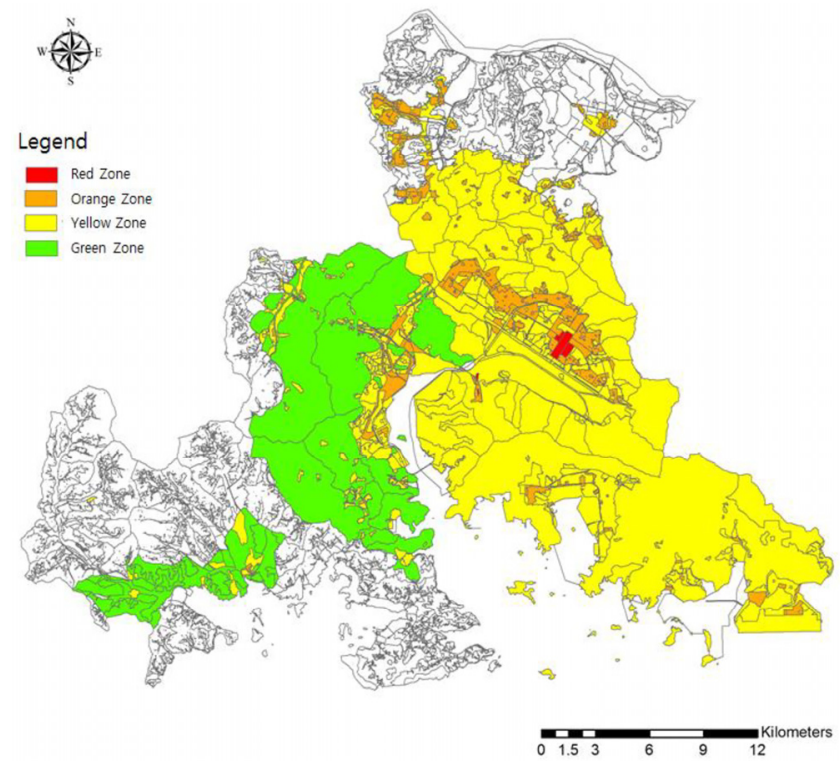

Fig. 4. Urban flood vulnerability analysis map. lower the flood risk level (no damage). Flood damage was prioritized, based on fuzzy analysis. When the same area was submerged, the area with the highest economic and social damage from the flood was the central commercial area, followed by the general commercial area, semi-residential area, distribution commercial area, neighborhood commercial areas, private residential areas, general residential areas, industrial areas, and green areas [23].

Based on the results of the vulnerability analysis, internal flooding risk classification by use districts in Changwon can be mapped (Fig. 4). The Red Zone includes the areas with the highest flood risk, followed by the Orange and Yellow Zones. The area with the lowest flood risk is delineated as the Green zone [23].

\subsection{Assessing Disaster Resilience of Urban Planning Facilities}

To evaluate the disaster recovery resilience of urban planning facilities, a network-based decision-making system called Analytic Network Process (ANP) was used to reflect mutual dependence or feedback in the analysis process.

The results of the resilience analysis of urban planning facilities are shown in Table 2. Disaster prevention facilities showed the highest resilience with a weighted value of 0.26268 ; followed by space facilities (0.23158); traffic facilities (0.17345); public, cultural, and athletic facilities (0.10694); environmental facilities (0.08835); health and sanitary facilities (0.07241); and distribution and supply facilities (0.06460). Disaster-prevention facilities are shown to have the highest resilience, as they have a direct disaster-prevention function. Space facilities have high resilience, as they have a detention function and an underground penetration function, enabling direct and indirect disaster prevention features [24].

Although traffic facilities can lead to paralysis of urban functions in the event of disaster damage, they are multi-faceted throughout the city and are more resilient, as they receive higher scores than other facilities for robustness and redundancy. This reflects the fact that public, cultural and athletic facilities can make notifications about various situations throughout a disaster, and can cope with damages by themselves. They also increase the resilience of the entire city, as they can provide space for evacuation and shelter.

Environmental facilities appeared to have very low resilience,

Table 1. Fuzzy Score of Vulnerability for Each Use District

\begin{tabular}{|c|c|c|c|c|c|c|c|c|}
\hline $\begin{array}{l}\text { Administrative } \\
\text { District }\end{array}$ & & Use District & $\begin{array}{l}\text { Land } \\
\text { Price }\end{array}$ & $\begin{array}{c}\text { Floor Area } \\
\text { Ratio }\end{array}$ & $\begin{array}{c}\text { Underground } \\
\text { Area }\end{array}$ & $\begin{array}{c}\text { Decline of } \\
\text { Building }\end{array}$ & Fuzzy & Priority \\
\hline \multirow{9}{*}{$\begin{array}{l}\text { Changwon } \\
\text { City }\end{array}$} & \multirow{3}{*}{$\begin{array}{c}\text { Residential } \\
\text { Area }\end{array}$} & Private Residential Area & 0.259 & 0.093 & 0.002 & 0.096 & 0.236 & 6 \\
\hline & & General Residential Area & 0.120 & 0.106 & 0.017 & 0.195 & 0.219 & 7 \\
\hline & & Semi-residential Area & 0.258 & 0.157 & 0.017 & 0.193 & 0.257 & 3 \\
\hline & \multirow{6}{*}{$\begin{array}{c}\text { Commercial } \\
\text { Area }\end{array}$} & Central Commercial Area & 0.354 & 0.273 & 0.055 & 0.101 & 0.367 & 1 \\
\hline & & General Commercial Area & 0.259 & 0.226 & 0.013 & 0.196 & 0.282 & 2 \\
\hline & & Neighborhood Commercial Area & 0.236 & 0.142 & 0.018 & 0.167 & 0.251 & 5 \\
\hline & & Distribution Commercial Area & 0.146 & 0.138 & 0.022 & 0.099 & 0.253 & 4 \\
\hline & & Industrial Area & 0.101 & 0.065 & 0.062 & 0.103 & 0.213 & 8 \\
\hline & & Green Area & 0.026 & 0.037 & 0.028 & 0.166 & 0.156 & 9 \\
\hline
\end{tabular}


Table 2. Resilience of Urban Planning Facilities

\begin{tabular}{|c|c|c|c|c|c|}
\hline Assessment Index & & Normalized by Cluster & Limiting & Weight & Priority \\
\hline \multirow{4}{*}{ Traffic facilities } & Robustness & 0.26084 & 0.04524 & \multirow{4}{*}{0.17345} & \multirow{4}{*}{3} \\
\hline & Redundancy & 0.27586 & 0.04785 & & \\
\hline & Rapidity & 0.22350 & 0.03877 & & \\
\hline & Resourcefulness & 0.23980 & 0.04159 & & \\
\hline \multirow{4}{*}{ Space facilities } & Robustness & 0.31187 & 0.07222 & \multirow{4}{*}{0.23158} & \multirow{4}{*}{2} \\
\hline & Redundancy & 0.28534 & 0.06608 & & \\
\hline & Rapidity & 0.29646 & 0.06865 & & \\
\hline & Resourcefulness & 0.10634 & 0.02463 & & \\
\hline \multirow{4}{*}{ Distribution and Supply facilities } & Robustness & 0.21840 & 0.01411 & \multirow{4}{*}{0.06460} & \multirow{4}{*}{7} \\
\hline & Redundancy & 0.23634 & 0.01527 & & \\
\hline & Rapidity & 0.23693 & 0.01531 & & \\
\hline & Resourcefulness & 0.30834 & 0.01992 & & \\
\hline \multirow{4}{*}{ Public, Cultural and Athletic facilities } & Robustness & 0.27298 & 0.02919 & \multirow{4}{*}{0.10694} & \multirow{4}{*}{4} \\
\hline & Redundancy & 0.13185 & 0.01410 & & \\
\hline & Rapidity & 0.27691 & 0.02961 & & \\
\hline & Resourcefulness & 0.31827 & 0.03403 & & \\
\hline \multirow{4}{*}{ Disaster-prevention facilities } & Robustness & 0.24703 & 0.06489 & \multirow{4}{*}{0.26268} & \multirow{4}{*}{1} \\
\hline & Redundancy & 0.21185 & 0.05565 & & \\
\hline & Rapidity & 0.35619 & 0.09357 & & \\
\hline & Resourcefulness & 0.18493 & 0.04858 & & \\
\hline \multirow{4}{*}{ Health and Sanitary facilities } & Robustness & 0.29419 & 0.02130 & \multirow{4}{*}{0.07241} & \multirow{4}{*}{6} \\
\hline & Redundancy & 0.11819 & 0.00856 & & \\
\hline & Rapidity & 0.30378 & 0.02200 & & \\
\hline & Resourcefulness & 0.28384 & 0.02055 & & \\
\hline \multirow{4}{*}{ Environmental facilities } & Robustness & 0.36202 & 0.03198 & \multirow{4}{*}{0.08835} & \multirow{4}{*}{5} \\
\hline & Redundancy & 0.28213 & 0.02493 & & \\
\hline & Rapidity & 0.23005 & 0.02032 & & \\
\hline & Resourcefulness & 0.12580 & 0.01111 & & \\
\hline
\end{tabular}

as they do not have disaster-prevention features and have a high risk of secondary damage. Although health and sanitary facilities, such as cemeteries, have indirect disaster-prevention features, those features appeared to be weak and their resilience was found to be very low, as human damage is expected if general medical facilities are damaged. Distribution and supply facilities generally do not have disaster prevention features and are the facilities most relevant to the daily lives of citizens, as discussed by Buneau et al. [8]. This is due to the high possibility of secondary damage from explosions or from other, more trivial incidents that bring great discomfort to living. Furthermore, these facilities appear to have the lowest resilience, as they are organically connected to each other and can cover a broad area, paralyzing the functions of the city.

Once the classifications of urban planning facilities are determined, resilience can be determined, based on the level of each risk. Facilities with very high resilience are classified as Class A, those with high resilience as Class B, those with medium resilience as Class C, and the lowest resilience are Class D. By overlaying these results on the map of Changwon, it is possible to see the classifications of the urban planning facilities, pursuant to the resilience analysis, in Fig. 5.

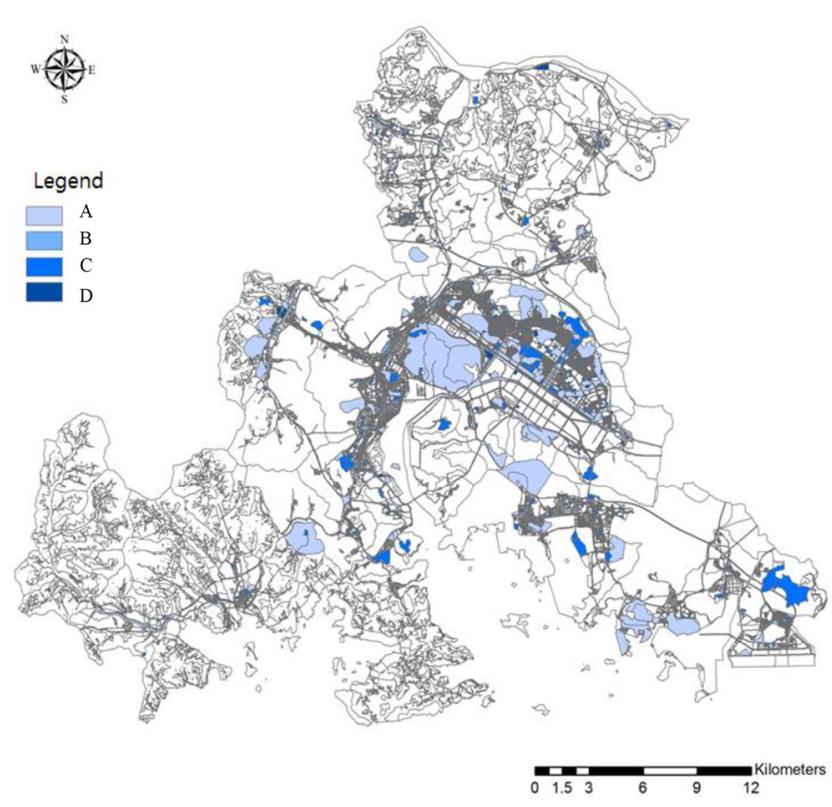

Fig. 5. Resilience classification map of urban planning facilities. 


\subsection{Assessment of the Appropriateness of Location of the Uurban Planning Facilities Based on Urban Flooding Risk}

The vulnerability analysis map and the urban planning facility classification map were combined, as shown in Fig. 6. The visualized data are expected to make it easier to understand and access, even for the general public. New towns have been developed in the areas of Seongsan-gu and Uichang-gu, and these areas were analyzed to be highly vulnerable, due to the high property value and high building density of commercial areas. A land use plan should be established for these towns by allocating the lowest vulnerability areas to the green area. In addition, some low-resilience urban planning facilities have been located in the Red Zone, which is highly vulnerable, and damage is likely to be more severe during and after flooding occurs. It is important to properly locate facilities with high resilience, such as disaster prevention facilities and space facilities. Locating highly resilient urban planning facilities in areas with high vulnerability, as emphasized in this study, would ensure that facilities that are more able to cope with and systematically manage flood damage are in those more vulnerable areas.

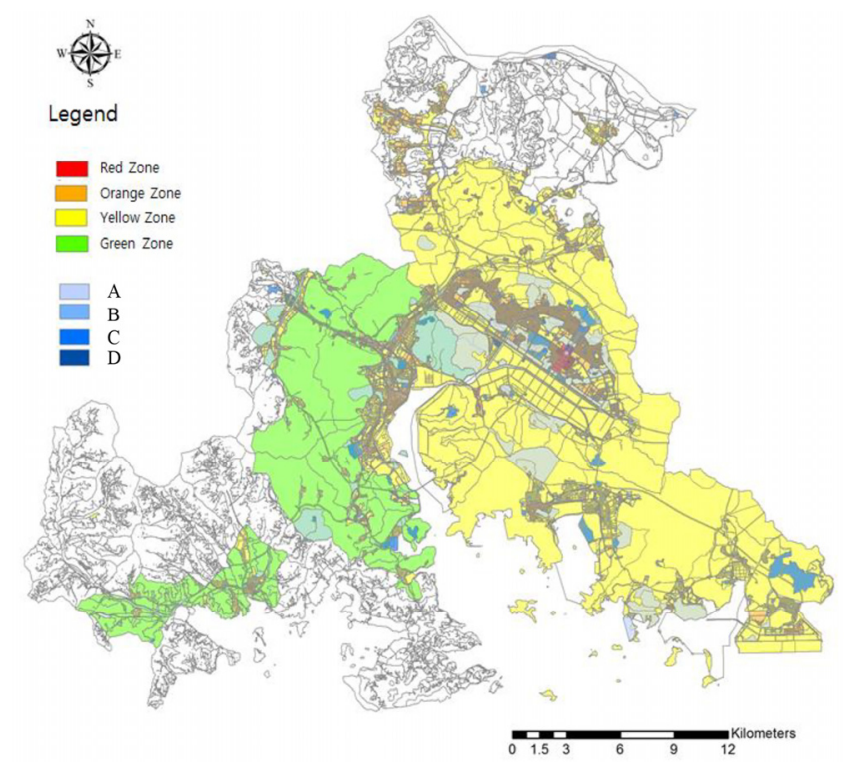

Fig. 6. Disaster resilience analysis map.

\section{Conclusions}

This study analyzed disaster resilience of urban spaces, alongside vulnerability to flooding, as an approach to minimize flood damage. Flood damage has one of the largest impacts among the problems related to climate change.

As a result of these analyses, the following conclusions were reached:

1) A method was developed to reduce urban-area flood damage during extreme rainfall events. The solution was found in the aspect of land use classifications, which are an urban planning measure that can supplement the limits of structural measures. The appropri- ateness of the locations of urban planning facilities can be determined by classifying land use through a vulnerability analysis and then classifying urban areas as to their levels of resilience. Overlaying one map on the other allows a visual assessment of whether facilities have been appropriately placed, with the goal of placing more resilient facilities in areas with higher vulnerability, and lower resilient facilities in areas of lower vulnerability. This approach has a potentially significant impact of promoting the minimization of flood damage through the optimization of land use.

2) This study classified land use by type of use, through a vulnerability assessment. It is possible to systematically manage zones and facilities through land use classification. It will be quite useful for land use planning to consider areas prone to floods when establishing urban-area development plans.

3) This study classified the resilience of urban planning facilities. Most urban planning facilities are in urban areas, and assets of considerable economic scale are required to enhance resilience for disaster response. Consequently, it is difficult for private sectors to make the required investments. Therefore, public institutions should secure safety through investment for the public interest. In addition, urban planning facilities are suitable for evaluating resilience, as they include facilities designed with the purposes of protecting against and preventing disaster.

4) This study developed an assessment method by determining that the vulnerability of the use areas and the resilience of urban planning facilities should form the basis for urban planning. This study also identified the land use characteristics, building characteristics, and so on; those make up the use areas and then analyzed the appropriateness of the layout of urban planning facilities within different use areas. If placement is strategic, damage from natural disasters can be minimized. This approach enables urban planning efforts to prospectively or retroactively place facilities in preferential areas.

5) This study identifies an approach to urban planning that can increase economic efficiency. Structural and technical measures involve difficulty in maintenance and management; however, in the case of land use measures, planning and implementing a well-thought-out plan, can eliminate or reduce the necessity for intensive maintenance and management. Considering the uncertainties in the future of climate change and the huge investment costs and time required to increase the capacity of disaster prevention facilities, there are clear limits to structural measures. On the other hand, this study suggests that measures based on land-use classifications of risk division and risk distribution are the most efficient and appropriate plans, in terms of urban planning, to increase shock absorption and resilience against flood damage.

\section{Acknowledgment}

This paper was financially supported by Ministry of the Interior and Safety as "Human resource development Project in Disaster management".

This article was presented at the 2019 International Desalination Workshop (IDW2019) held on 28-30 August 2019, Jeju, Korea. 


\section{Author Contributions}

K.Y.P. (Associate professor) conceptualized the research, performed the formal analysis, and wrote the first draft of the paper. H.O. (Ph.D. course) analyzed and discussed the results. J.H.W. (Professor) provided feedback on the research approach, and reviewed the first draft of the paper. All authors revised the paper and agreed on the final version of the paper.

\section{References}

1. Mailhot A, Duchesne S, Caya D, Talbot G. Assessment of future change in intensity-duration-frequency (IDF) curves for Southern Quebec using the Canadian Regional Climate Model (CRCM). J. Hydrol. 2007;347:197-210.

2. Katz RW, Brown BG. Extreme events in a changing climate: variability is more important than averages. Clim. Change 1992;21:289-302.

3. IPCC. Contribution of working group I to the fifth assessment report of the Intergovernmental panel on climate change. Cambridge, United Kingdom and New York, NY, USA: Cambridge University Press; 2013.

4. Godschalk DR. Urban hazard mitigation: Creating resilient cities. Nat. Hazards Rev. 2003;4:136-143.

5. Ponce J. Land use planning and disaster: A European perspective from Spain. Oñati socio-leg. 2013;3:196-220.

6. Park K, Lee MH. The development and application of the urban flood risk assessment model for reflecting upon urban planning elements. Water 2019;11:920.

7. Fussel HM, Klein RJT. Climatic change vulnerability assessments: An evolution of conceptual thinking. Clim. Change 2006;75:301-167.

8. Bruneau M, Chang SE, Eguchi RT, et al. A framework to quantitatively assess and enhance the seismic resilience of communities. Earthq. Spectra. 2003;19:733-752.

9. Liverman DM. Vulnerability to global environmental change. Understanding Global Environmental Change: The Contributions of Risk Analysis and Management. The Earth Transformed Programme. Worcester: MA, Clark University.
1990. p. 27-44.

10. Zimmerman R. Social implications of infrastructure network interactions. J. Urban Technol. 2001;8:97-119.

11. Tierney K, Bruneau M. Conceptualizing and measuring resilience: A key to disaster loss reduction. Transportation Research News; 2007. P. 14-17.

12. McDaniels T, Chang S, Cole D, Mikawoz J, Longstaff H. Fostering resilience to extreme events within infrastructure systems: Characterizing decision contexts for mitigation and adaptation. Global Environ. Change 2008;18:310-318.

13. Norman B. Principles for an intergovernmental agreement for coastal planning and climate change in australia. Habitat Int. 2008;33:293-299.

14. Bankoff G. Time is of the essence: Disasters, vulnerability and history. Int. J. Mass Emerg. Disasters. 2004;22:23-42.

15. Manyena SB. The concept of resilience revisited. Disasters 2006;30:433-450.

16. Klein R, Nicholls R, Thomalla F. Resilience to natural hazards: How useful is this concept? Environ. Hazards 2003;5:35-45.

17. Cutter SL, Barnes L, Berry M, et al. A place-based model for understanding community resilience to natural disasters. Global Environ. Change 2008;18:598-606.

18. Ministry of the Interior and Safety. 2016 Statistical yearbook of natural disaster. Sejong city. Republic of Korea; 2017.

19. Zadeh LA. Fuzzy sets. Inf. Control 1965;8:338-353.

20. Chang N, Chen HW, Ning SK. Identification of river water quality using the Fuzzy Synthetic Evaluation approach. J. Environ. Manag. 2001;63:293-305.

21. Saaty TL. Theory and applications of the analytic network process: Decision Making with Benefits, Opportunities, Costs, and Risks. RWS Publications; 2005.

22. Ministry of Land, Infrastructure and Transport. A Study on the effective reducing for prevention the urban flood damage; 2008. P. 1-346.

23. Park K, Lee MH. Vulnerability analysis of urban district on the urban flood damage. Desalin. Water Treat. 2018;119:27-35.

24. Park K, Won J. Evaluation of disaster resilience of urban planning facilities against urban flood. J. Korean Soc. Hazard Mitig. 2019;19:47-57. 